\title{
Utility of Hypertonic Saline in the Management of Acute Bronchiolitis in Infants: A Randomised Controlled Study
}

\author{
Sadbhavna Pandit ${ }^{\mathrm{a}}$, Neeraj Dhawana, ${ }^{\mathrm{a}}$, Deepak Thakur ${ }^{\mathrm{a}, \mathrm{b}}$
}

\begin{abstract}
Background: Bronchiolitis is a common lower respiratory tract ailment usually affects infants. With few effective treatments, the health care cost of managing bronchiolitis is significant; Cochrane data base review has cited sufficient evidence regarding the usefulness of hypertonic saline in cystic fibrosis patients. Hypertonic saline has recently been given a trial in patients with acute bronchiolitis. We undertook the study to determine the efficacy and safety of hypertonic saline (3\%) plus adrenaline nebulisation in bronchiolitis in infants and to compare it with normal saline $(0.9 \%)$ plus adrenaline nebulisation.
\end{abstract}

Methods: One hundred consecutive patients attending Paediatrics Emergency at GMSH, Sector-16, Chandigarh between the age group of 2 to 12 months and admitted with clinical diagnosis of acute bronchiolitis were enrolled for the study.

Results: Baseline clinical symptoms and signs were comparable between the two groups. There was no significant difference found between 2 groups in relation to clinical signs (respiratory rate, RDAI, heart rate and $\mathrm{SpO}_{2}$ ) pre and post nebulisation on day 1 as well as on day 2. The change in clinical parameters pre and post nebulisation in 2 groups was comparable. The mean \pm SD length of stay in hospital in hypertonic saline and normal saline group was $3.92 \pm 1.72$ days and $4.08 \pm 1.90$ days respectively. There was no significant difference noted between two groups $(\mathrm{P}=0.67)$.

Conclusion: Nebulisation with hypertonic saline plus adrenaline and normal saline plus adrenaline are equally effective in the treatment of acute bronchiolitis in infants. Nebulisation with hypertonic saline is a safe option of treatment in acute bronchiolitis in children.

Manuscript accepted for publication May 14, 2013

${ }^{a}$ Department of Paediatrics, G.M.S.H., Sec- 16, Chandigarh, India ${ }^{\mathrm{b}}$ Corresponding authors: Deepak Thakur, Good Health Clinic, Phawara Chowk, Sirhind, Distt. Fathegarh Sahib, Punjab (Pin-140406), India. Email: deepak_130505@yahoo.com; Neeraj Dhawan, Department of Paediatrics, New O.P.D., G.M.S.H., Sec- 16, Chandigarh, India.

Email: ndhawan_6144@yahoo.com

doi: http://dx.doi.org/10.4021/ijcp96w
Keywords: Bronchiolitis; Hypertonic saline; Adrenaline; Nebulisation; Respiratory distress assessment instrument score

\section{Introduction}

Acute viral bronchiolitis is the most common acute infection of the lower respiratory tract during the first year of life [1]. Bronchiolitis is defined as "a constellation of clinical symptoms and signs including a viral upper respiratory prodrome followed by increased respiratory effort and wheezing in children less than 2 years of age [2]". Respiratory synctial virus (RSV) is responsible for about $80 \%$ of cases, it is estimated that around $2-3 \%$ of all the infants younger than 1 year are admitted to the hospital with bronchiolitis usually during the seasonal epidemics. The pathologic picture that occurs in the airways of children with bronchiolitis is important in understanding the clinical manifestations and developing rational management [3]. The viral infection occurs through the upper respiratory tract and spreads lower within a few days, resulting in inflammation of the bronchiolar epithelium, with peribronchial infiltration of white blood cell types, mostly mononuclear cells and edema of the sub mucosa and adventitia [4]. Bronchiolitis is an active area of research and many important studies, reviews and met analysis have advanced the understanding of this disorder in the past few years. Different studies have been conducted to find and prove the ideal treatment for this disorder using different agents and various combinations of agents [5]. In 2009 Cochrane Database of Systematic Review Linjie Zhang et al [6] conducted an interventional review to access the effects of nebulised hypertonic saline solution in infants with acute viral bronchiolitis. The review concluded that the effect of nebulised hypertonic saline in improving clinical score was greater among outpatients than inpatients. No adverse events related to $3 \%$ saline inhalation were reported. While there is a lack of strong evidence to support the routine use of aerosolised hypertonic saline solution in children with acute viral bronchiolitis due to limited number of RCT's, the lack of side effects and the limited cost of the treatment deserve consideration for a large RCT. Infants suffering from severe 
Table 1. RDAI Score Table

\begin{tabular}{|c|c|c|c|c|c|c|}
\hline & $\mathbf{0}$ & 1 & 2 & 3 & 4 & $\begin{array}{l}\text { Maximum } \\
\text { Points }\end{array}$ \\
\hline \multicolumn{7}{|l|}{ Wheezing } \\
\hline Expiratory & None & End & Half & $3 / 4$ th & All & 4 \\
\hline Inspiratory & None & Part & All & & & 2 \\
\hline Location & None & $\begin{array}{l}\text { Segmental, } 2 \text { of } 4 \text { lung } \\
\text { fields }\end{array}$ & $\begin{array}{l}\text { Diffuse, } 3 \text { of } 4 \text { Lung } \\
\text { fields }\end{array}$ & & & 2 \\
\hline \multicolumn{7}{|l|}{ Retractions } \\
\hline $\begin{array}{l}\text { Supra } \\
\text { Clavicular }\end{array}$ & None & Mild & Moderate & Marked & & 3 \\
\hline Intercostal & None & Mild & Moderate & Marked & & 3 \\
\hline Subcostal & None & Mild & Moderate & Marked & & 3 \\
\hline
\end{tabular}

acute RSV bronchiolitis, the high load of RSV infection in the small bronchioles probably causes a considerable reduction of extra cellular ATP by increasing ATPase levels decreasing extra cellular ATP and therefore results in loss of $\mathrm{ENaC}$ inhibition (increasing $\mathrm{Na}$ absorption) and loss of the attenuation of outward secretion of chloride. Thus, more water will move from the airway surface liquid (ASL) to the sub-mucosa along with these electrolytes. This will result in more dehydration of the ASL and a decrease in the height of the mucus layer. The role of hydration of the airway surface liquid (ASL) and the importance of inhaled hypertonic saline for rehydration have been recently reviewed [7-9]. Hypertonic saline breaks the ionic bonds within the mucus gel, thereby reducing the degree of cross linking and entanglements and lowering the viscosity and elasticity of the mucus secretion [10]. Hypertonic saline induces an osmotic flow of water into the mucus layer rehydrating secretions and improving mucus rheology. Hypertonic saline stimulates cilial beat via the release of prostaglandin $\mathrm{E}_{2}$ [11]. Moreover, by absorbing water from the mucosa and sub mucosa, hypertonic saline solution can theoretically reduce oedema of airway wall in infants with acute bronchiolitis $[12,13]$. Hypertonic saline inhalation can also cause sputum induction and cough, which can help to clear the sputum outside of bronchi and thus improve airway obstruction [12].

The above mentioned theoretical benefits provide the rationale for the treatment of acute bronchiolitis with nebulised hypertonic saline solution.

\section{Materials and Methods}

The study was a prospective, randomised controlled, nonblinded study. Written informed consent was obtained from the parents or guardians accompanying the child before participation in the trial. Parents were explained that the patients

Table 2. Length of Stay in Hospital

\begin{tabular}{lllc}
\hline Group & $\begin{array}{l}\text { Mean } \pm \text { SD } \\
\text { (in days) }\end{array}$ & $\begin{array}{l}\text { Range of stay } \\
\text { (in days) }\end{array}$ & P value \\
\hline A & $3.92 \pm 1.72$ & $1-10$ & 0.670 \\
B & $4.08 \pm 1.90$ & $1-12$ \\
Total & $4.00 \pm 1.80$ & $1-12$ \\
\hline
\end{tabular}


Table 3. Clinical Parameters Pre and Post Nebulisation in Both the Groups on Day 1 of Admission

\begin{tabular}{|c|c|c|c|c|c|}
\hline \multirow{2}{*}{ Clinical parameter } & \multirow{2}{*}{ Group } & \multicolumn{2}{|c|}{ Before treatment } & \multicolumn{2}{|c|}{ After treatment } \\
\hline & & $($ Mean \pm SD $)$ & P value & $($ Mean \pm SD $)$ & P value \\
\hline \multirow[t]{2}{*}{ Respiratory rate } & $\mathrm{A}(\mathrm{n}=51)$ & $70 \pm 5.4$ & 0.09 & $66.2 \pm 5.3$ & \multirow{2}{*}{0.21} \\
\hline & $\mathrm{B}(\mathrm{n}=49)$ & $68.5 \pm 3.7$ & & $64.2 \pm 4.2$ & \\
\hline \multirow[t]{2}{*}{ RDAI } & $\mathrm{A}(\mathrm{n}=51)$ & $12 \pm 1.7$ & 0.29 & $10.5 \pm 1.7$ & \multirow[b]{2}{*}{0.75} \\
\hline & $\mathrm{B}(\mathrm{n}=49)$ & $11.7 \pm 1.3$ & & $10.3 \pm 1.7$ & \\
\hline \multirow[t]{2}{*}{ Heart rate } & $\mathrm{A}(\mathrm{n}=51)$ & $131.7 \pm 11.3$ & 0.74 & $128.8 \pm 11.25$ & \multirow[b]{2}{*}{0.39} \\
\hline & $\mathrm{B}(\mathrm{n}=49)$ & $130.7 \pm 10.5$ & & $126.5 \pm 10.14$ & \\
\hline \multirow[t]{2}{*}{$\mathrm{SpO} 2$} & $\mathrm{~A}(\mathrm{n}=51)$ & $90.82 \pm 4.57$ & 0.66 & $93.20 \pm 3.75$ & \multirow[b]{2}{*}{0.38} \\
\hline & $\mathrm{B}(\mathrm{n}=49)$ & $90.57 \pm 4.2$ & & $92.55 \pm 4.0$ & \\
\hline
\end{tabular}

would be monitored for any signs of deterioration during the study period. Each child was subjected to minimum routine investigations and hence explained that it was unlikely to impose any extra risk to the patient. Each patient was free to withdraw from the treatment during the study and he would not be denied treatment at any level. Both the normal saline and hypertonic saline was supplied by the hospital, no extra financial burden was put on the patient's family. This was a non funded study.

The Ethical committee of the institute approved this study. This trial was registered at Clinical Trial Registry of India, New Delhi vide no. CTRI/2010/091/000080. One hundred consecutive patients attending Paediatrics Emergency at GMSH, Sector-16, Chandigarh between the age group of 2 to 12 months and admitted with clinical diagnosis of acute bronchiolitis were enrolled for the study. Criteria for clinical diagnosis of acute bronchiolitis were short history of cough with or without fever of less than seven days duration and wheezing on examination and with the first attack of wheezing.

\section{Exclusion criteria}

(1). Patient with recurrent episodes of wheezing, one or more episodes of respiratory distress in past. (2). Patients with family history of asthma, atopy. (3). Presence of congenital heart disease. (4). History of prematurity or mechanical ventilation in newborn period. (5). Very sick patients with shock, seizures, heart rate $>180 / \mathrm{min}$, respiratory rate $>100 / \mathrm{min}$ and adjudged to be in incipient respiratory failure. (6). Grade III and IV PEM. (7). Consolidation lung on X-ray chest. (8). No child to be included in the study twice.

\section{Methodology}

After satisfying inclusion and exclusion criteria, written informed consent was taken from attendant of the patient and he was free to withdraw from the study any time. After the selection of patient of acute bronchiolitis, they were randomly allocated to group A and B by a computer generated random number table (unequal number). Group allocation was concealed in an opaque envelope. After enrolment, envelope was opened and patient was assigned to a specific group. In group A (hypertonic saline group), $4 \mathrm{~mL}$ of $3 \%$ hypertonic saline and $1 \mathrm{~mL}$ of 1:1,000 adrenaline was given as nebulisation with oxygen flow of 6 - 8 litre/min. In group B (normal saline group), $4 \mathrm{~mL}$ of normal saline $(0.9 \%)$ and $1 \mathrm{~mL}$ of 1:1,000 adrenaline was given as nebulisation. The nebulisation was given three times with an interval of one hour between two nebulisations; assessment of patient as respiratory rate, respiratory distress assessment instrument score, heart rate, oxygen saturation was done on admission that is before the nebulisation and half an hour after third nebulisation. There after nebulisation was given six hourly to patients in each group with respective saline and adrenaline on subsequent days till discharge. Discharge criteria were respiratory rate less than 60/min, without any retractions and wheezing. During hospital stay, patients were daily assessed once for their respiratory rate, RDAI, heart rate, oxygen saturation before and half an hour after nebulisation.

RDAI Score Table is shown in Table 1. Based on RDAI score, respiratory distress was graded into moderate $(6-12)$ 
and severe $(>12)$ grades.

\section{Outcomes}

Primary outcome: length of hospital stay. Secondary outcome: improvement in RDAI score, respiratory rate, haemoglobin saturation, heart rate, number of add on treatment, adverse events (tachycardia, pallor, tremor, nausea, vomiting).

\section{Sample size}

In the study by Kuzik et al [14] the results showed $26 \%$ reduction in hospital length of stay in the hypertonic saline group, based on this study sample size calculated was 100 with $80 \%$ power and confidence interval of $95 \%$. This sample size was calculated using EPIINFO 06 soft ware.

\section{Statistical analysis}

All continuous variables were examined using the paired or unpaired t test as appropriate. Non continuous variables were examined using $x^{2}$ test. The mean \pm SD (with $95 \%$ confidence interval) expresses the central tendency of the data. To examine the change in clinical severity score after nebuliser, paired t test was carried out in each treatment group separately. For the analysis, a $\mathrm{P}$ value $<0.05$ was considered significant.

\section{Results}

This study was carried out at Government Multi Speciality Hospital Sector-16, Chandigarh during the period from $1 / 11 / 2009$ to $31 / 05 / 2011$. During this period of 19 months, 100 subjects were enrolled under group A (study group) and group B (control group). There were 51 patients in group A and 49 patients in group B. Out of 100 cases there was no drop outs, no deaths and all the cases recovered irrespective of the group they were enrolled in.

Patients in group A and group B were comparable with respect to demographic data, clinical profile and baseline investigations as age, sex ratio, immunisation status, fever, haemoglobin, total leukocyte count, where as symptoms and signs like cough, fast breathing and wheezing were constant features and were present in all the subjects at the time of admission.

\section{Primary outcome}

In group A, the hospital stay of patients ranged from 1 to 10 days with mean stay of 3.9 days. In group B, the hospital stay of patients ranged from 1 to 12 days with mean stay of 4.0 days. There was no significant difference found between two groups in relation to length of stay in the hospital $(\mathrm{P}=$
0.670) (Table 2).

The length of hospital stay was significantly higher ( $\mathrm{P}$ $<0.05)$ in patients who received other treatment modalities like antibiotics (33\%), steroids (4\%) and other bronchodilators $(15 \%)$ as compared to patients who were not given these add on treatments.

\section{Secondary outcome}

In group $\mathrm{A}$ the mean value for RDAI, respiratory rate, heart rate and $\mathrm{SpO}_{2}$ pre nebulisation on day 1 of admission were $12.00,70.76,131.76,90.82$ respectively and post nebulisation on day 1 mean value of RDAI, respiratory rate, heart rate and spo2 were $10.51,66.16,128.82,93.20$ respectively. Where as in group B the mean values for RDAI, respiratory rate, heart rate and spo 2 pre nebulisation on day 1 of admission were $11.71,68.49,130.73,90.57$ respectively as compared to post nebulisation value of $10.31,64.20,126.53$ and 92.55 respectively. The results showed no significant difference in the clinical parameters compared between 2 groups $(\mathrm{P}>0.05)$ (Table 3).

The results did show a significant improvement in the clinical parameters that were respiratory rate, RDAI score, heart rate and $\mathrm{SpO} 2$ pre to post nebulisation within group $\mathrm{A}$ and similar improvement in clinical parameters was found in group B as well $(\mathrm{P}<0.05)$ on day 1 of admission. Similarly results showed no significant difference in the clinical parameters on day 2 of admission compared in both the groups $(\mathrm{P}>0.05)$. On comparison of the number of patients between two groups who received the add on treatment, the outcome measures did not show significant difference between two groups regarding usage of antibiotics, steroids, other bronchodilator usage $(\mathrm{P}>0.05)$. Out of the total 100 infants, side effects were noted in 4 (4\%) infants (vomiting-3, diarrhoea$1)$; all were enrolled under group B. there were no adverse affects as tremors or paleness in any patient during treatment.

\section{Discussion}

Limited studies have been published from India and abroad regarding use of hypertonic saline with adrenaline nebulisation in bronchiolitis in children. We undertook the study to establish the therapeutic role for hypertonic saline solution in acute bronchiolitis. This modality may provide a cheap and effective therapy for children with acute bronchiolitis.

In our study all infants recovered in both the groups, there was no treatment failure or significant adverse events following nebulisation, there was no significant difference found between group A and B in relation to the primary outcome that was length of stay in hospital $(\mathrm{P}=0.670)$. Even secondary outcome that were clinical parameters like respiratory rate, $\mathrm{RDAI}$, heart rate and $\mathrm{SpO}_{2}$ were comparable between both the groups $\mathrm{A}$ and $\mathrm{B}$ recorded on day 1 and day 2 
of admission with no significant difference in these parameters $(\mathrm{P}>0.05)$. The results in our study did show significant improvement in clinical parameters (RDAI, respiratory rate and $\left.\mathrm{SpO}_{2}\right)$ pre to post nebulisation in group $\mathrm{A}$ and $\mathrm{B}(\mathrm{P}<$ 0.05 ) recorded on day 1 and 2 of admission.

Brain A. Kuzik et al [14] in his study found that the infants in hypertonic saline group had statistically significant $(26 \%)$ reduction in length of hospital stay as $2 \pm 1.9$ days compared with $3.5 \pm 2.9$ days in normal saline group $(\mathrm{P}=0.05)$. Avigdor Mandelberg et al [12] in their trial on 52 hospitalised infants showed significant improvement in clinical severity score on respective days of hospitalisation and significantly reduced days of stay in hospital $(\mathrm{P}<0.05)$. In study done by Guy Tal et al [15] the pattern of response with respect to clinical score at day 1 and 2 after inhalation and mean duration of hospitalization was $3.6 \pm 1.7$ days for Group I and 2.8 \pm 1.3 days for Group II, the hospital stay and clinical score was less in hypertonic saline group $(\mathrm{P}<0.05)$. Zhengxiu luo et al [16] showed improvement in clinical symptoms and signs (cough, wheezing and moist crackles) $\mathrm{P}<0.05$ and even the length of hospital stay $(\mathrm{P}<0.01)$ was less in the treatment group $(2.5 \mathrm{mg}$ salbutamol dissolved in $4 \mathrm{ml}$ hypertonic saline). Our study was in line with the studies by Simran Grewal et al [17], Ilke Ozahi Ipek et al [18] and Ayse Berna Anil et al [19] which showed no significant difference in the hypertonic saline group versus other groups.

The incidence of side effects was $4 \%$ in our study. The side effects noted in our study was vomiting in 3 infants and diarrhoea in 1 infant, all were recorded in group B. However the severity of vomiting and diarrhoea was not to the extent to necessitate withdrawal of the treatment. Other uncommon side effects including tremors, tachycardia and pallor were not seen in our study.

Limitations of the study were its non-blinded study design, which would have introduced some bias during evaluation, our patient population included only hospitalised infants $\leq 12$ months and did not include outdoor patients with mild illness, patients were enrolled based on clinical diagnosis and not confirmed by viral studies, the exact duration of hypertonic saline effect (half life) and therefore its continuing impact on clinical parameter is not known and should be investigated further. The strength of this study was its randomised control design using standard protocol and strict sequential allocation of infants in 2 groups resulted in good match for reported symptoms, signs on examination and laboratory findings at presentation. Two arm treatment groups had strengthened the comparison to infer the results and tried to remove bias in hospitalised patients to validate the dose for nebulisation administered. Our study evaluated efficacy in non critically sick admitted patients with acute bronchiolitis.

Also, there were no dropouts or withdrawal of patients during the study period in either group which strengthen confidence in outcome.
We conclude that Nebulisation with hypertonic saline plus adrenaline and normal saline plus adrenaline are equally effective in the treatment of acute bronchiolitis in infants. Nebulisation with hypertonic saline is a safe option of treatment in acute bronchiolitis in children.

\section{Acknowledgement}

Assistance with the study: none except the authors.

\section{Authors' Role}

Dr. Neeraj dhawan: Selected and designed the study. Dr. Deepak thakur: Enrolled the patients and prepared the results. Dr. Sadbhavna pandit and Dr. Neeraj dhawan: Critical review of the study.

\section{Financial Support and Sponsorship}

None.

\section{Conflict of Interest}

None.

\section{References}

1. Smyth RL, Openshaw PJ. Bronchiolitis. Lancet. 2006;368(9532):312-322.

2. Diagnosis and management of bronchiolitis. Pediatrics. 2006;118(4):1774-1793.

3. Hall CB. Respiratory syncytial virus and parainfluenza virus. N Engl J Med. 2001;344(25):1917-1928.

4. Williams JV, Tollefson SJ, Heymann PW, Carper HT, Patrie J, Crowe JE. Human metapneumovirus infection in children hospitalized for wheezing. J Allergy Clin Immunol. 2005;115(6):1311-1312.

5. Glezen WP. Morbidity associated with the major respiratory viruses. Pediatr Ann. 1990;19(9):535-536, 538, 540, passim.

6. Zhang L, Mendoza-Sassi RA, Wainwright C, Klassen TP. Nebulized hypertonic saline solution for acute bronchiolitis in infants. Cochrane Database Syst Rev. 2008;(4):CD006458.

7. Donaldson SH. Hydrator therapies for cystic fibrosis lung disease. Pediatr Pulmonol 2008;43:S18-S23..

8. Randell SH, Boucher RC. Effective mucus clearance is essential for respiratory health. Am J Respir Cell Mol Biol. 2006;35(1):20-28. 
9. Boogaard R, de Jongste JC, Merkus PJ. Pharmacotherapy of impaired mucociliary clearance in non-CF pediatric lung disease. A review of the literature. Pediatr Pulmonol. 2007;42(11):989-1001.

10. Ziment I. Respiratory pharmacology and therapeutics. Philadelphia: WB Saunders; 1978.

11. Daviskas E, Anderson SD. Hyperosmolar agents and clearance of mucus in the diseased airway. J Aerosol Med. 2006;19(1):100-109.

12. Mandelberg A, Tal G, Witzling M, Someck E, Houri S, Balin A, Priel IE. Nebulized 3\% hypertonic saline solution treatment in hospitalized infants with viral bronchiolitis. Chest. 2003;123(2):481-487.

13. Sarrell EM, Tal G, Witzling M, Somekh E, Houri S, Cohen HA, Mandelberg A. Nebulized 3\% hypertonic saline treatment in ambulatory children with viral bronchiolitis decreases symptoms. Chest 2002;122:215-220.

14. Kuzik BA, Al-Qadhi SA, Kent S, Flavin MP, Hopman W, Hotte S, Gander S. Nebulized hypertonic saline in the treatment of viral bronchiolitis in infants. J Pediatr. 2007;151(3):266-270, 270 e261.

15. Tal G, Cesar K, Oron A, Houri S, Ballin A, Mandelberg
A. Hypertonic saline/epinephrine treatment in hospitalized infants with viral bronchiolitis reduces hospitalization stay: 2 years experience. Isr Med Assoc J. 2006;8(3):169-173.

16. Luo Z, Liu E, Luo J, Li S, Zeng F, Yang X, Fu Z. Nebulized hypertonic saline/salbutamol solution treatment in hospitalized children with mild to moderate bronchiolitis. Pediatr Int. 2010;52(2):199-202.

17. Grewal S, Ali S, McConnell DW, Vandermeer B, Klassen TP. A randomized trial of nebulized 3\% hypertonic saline with epinephrine in the treatment of acute bronchiolitis in the emergency department. Arch Pediatr Adolesc Med. 2009;163(11):1007-1012.

18. Ipek IO, Yalcin EU, Sezer RG, Bozaykut A. The efficacy of nebulized salbutamol, hypertonic saline and salbuta$\mathrm{mol} /$ hypertonic saline combination in moderate bronchiolitis. Pulm Pharmacol Ther. 2011;24(6):633-637.

19. Anil AB, Anil M, Saglam AB, Cetin N, Bal A, Aksu N. High volume normal saline alone is as effective as nebulized salbutamol-normal saline, epinephrine-normal saline, and 3\% saline in mild bronchiolitis. Pediatr Pulmonol. 2010;45(1):41-47. 